\title{
Motivation for Gluten-Free Diet Adherence among Adults with and without a Clinically Diagnosed Gluten-Related Illness
}

\author{
Sarah E. Pember ${ }^{1}$ and Sarah E. Rush ${ }^{2}$ \\ ${ }^{1}$ The University of Alabama, Department of Health Science \\ 2 James Madison University
}

\begin{abstract}
Background and Purpose: Historically used as the sole treatment for celiac disease, there has been a substantial rise in popularity of the gluten-free diet (GFD) as both a diet plan and alternative form of medicine in the United States (US). Approximately 1\% of the US population suffers from celiac disease, but various reports show $30 \%$ to $80 \%$ of adults have an interest in, or are currently adhering to, a GFD. This study aimed to understand this disproportion by exploring GFD adherence motivations, in addition to medical diagnoses, within a population of gluten-free followers. Methods. An anonymous, internetbased survey was administered to assess GFD motivations and adherence within the general population $(\mathrm{n}=99)$. Results. Of those currently following or who had previously followed a GFD, medical diagnosis was reported by only $28.6 \%$ as motivation for GFD adherence, with $60.7 \%$ reporting general health motivations, $25.0 \%$ reporting weight loss motivations, and $21.4 \%$ reporting curiosity. Conclusion. This study supports previous research suggesting that adherence to a GFD may occur for reasons outside of a medical diagnosis. Public health educators should inform individuals about risks and misconceptions associated with GFDs when implementing healthy eating programs for adults without medically diagnosed digestive conditions.
\end{abstract}

(c) 2016 Californian Journal of Health Promotion. All rights reserved.

Keywords: gluten-free diets, celiac disease, fad diets, dietary motivation

\section{Introduction}

During the past decade, there has been a substantial increase in the popularity of the gluten-free diet (GFD). It is estimated that up to 100 million Americans will consume gluten-free products within one year (Fasano, Sapone, Zevallos, \& Schuppan, 2015). Although initially considered a dietary trend, sales of gluten-free products reached $\$ 8.8$ billion in sales in 2014, an increase of 63\% from 2012 (Marshall, 2014). Despite this substantial growth, little is known about consumer motivations for purchasing gluten-free products or choosing to follow a GFD.

Strict adherence to a GFD is the sole treatment for both celiac disease and gluten sensitivity. Celiac disease is a clinically diagnosed, chronic, digestive illness that causes malabsorption of nutrients in the intestines, and is triggered by gluten, a protein found in wheat, barley, and rye
(Fasano et al., 2003; Godfrey et al., 2010; Rubio-Tapia et al., 2009). Gluten sensitivity is a similar, although less severe, condition, with symptoms also triggered by the ingestion of gluten (Ludvigsson et al., 2012). While approximately $1 \%$ of the United States (US) population actually suffers from celiac disease, only $18 \%$ of GFD followers have been diagnosed with celiac disease and only $6 \%$ have been diagnosed with gluten-sensitivity (Marshall, 2014; Sapone et al., 2012). The prevalence of reported gluten sensitivity cases among the general population, and the prevalence of adults following a GFD or purchasing gluten-free products do not equate, indicating that there may be motivations aside from a medical prescription behind this dietary decision.

There are numerous health claims associated with the GFD, such as a treatment for psoriasis, irritable bowel syndrome, and acne, or as a 
weight loss strategy (Dunn, House, \& Shelnutt, 2014). However, adhering to a GFD without a medical diagnosis may actually be unhealthy, causing individuals to avoid foods with many nutritional benefits such as B vitamins, iron, and fiber (Hallert Svensson, Tholstrup, \& Hultberg., 2009; Howard et al., 2002; Ohlund, Olsson, Hernell, \& Ohlund, 2010; Wild, Robins, Burley, \& Howdle, 2010). Disproportionate adherence to GFDs, despite this information, suggests that publicly disseminated information about the purpose and benefits of GFDs may be misleading. To better understand the motivations for GFD adherence, especially among individuals lacking a clinically diagnosed digestive disorder, this study aimed to compare GFD adherence motivation in both clinically and non-clinically diagnosed populations of GFD followers.

\section{Methods}

\section{Study Design}

This was an online, cross-sectional survey study, designed by researchers with expertise in nutrition education and disordered eating and administered for purposes of exploring GFD adherence motivations among adults.

\section{Measures}

The Internet-based survey instrument included demographic variables (race, ethnicity, gender, and age) as well as a number of questions related to GFD adherence and motivation, examining gluten-related morbidity or disease diagnoses, general motivations for GFD adherence, and reasons for no longer following a GFD, if applicable. All questions were in a multiple response format where participants were instructed to "check all those that apply." The 5item Celiac Dietary Adherence Test (CDAT), which has been validated in populations of biopsy-proven celiac cases (Leffler, et al., 2009) was used to assess GFD adherence. There was no intake assessment, as participants were expected to respond honestly to questions regarding adherence to GFD.

\section{Sample}

The target population consisted of adults who were currently following or had previously followed, a GFD. Participants were recruited online through social media networking sites and e-mail using snowball sampling. The initial round of recruitment included a convenience sample of known GFD followers. The sample $(\mathrm{n}=99)$ was predominantly white $(68.2 \%)$, female (90.6\%), and ranged in age from 19 to 63 years old.

\section{Procedures}

Following IRB approval for all methods and materials from a public university in the southeastern United States, an anonymous, internet-based survey was created and administered to assess motivations for GFD adherence. Recruitment was conducted entirely online. The purpose of this sampling technique was to acquire a geographically diverse sample, rather than restricting data collection to one specific geographic area. To increase the number of GFD adherents in the participant population, purposive snowball sampling was utilized.

\section{Analyses}

After examining frequency and descriptive data, a series of ANOVA and chi-squared analyses were conducted to observe relationships among variables. All statistical analyses were completed using SPSS Version 22.0. Due to the small sample size, significance levels were set $a$ priori at $\mathrm{p}<0.10$.

\section{Results}

Frequencies for categories of respondents are included in Table 1 . Of those who were currently following or had previously followed a GFD, 37.4\% did not have a medical diagnosis for gluten-related illness or intolerance. Descriptive analyses showed $10.2 \%$ of respondents had a clinical diagnosis for celiac disease and $13.3 \%$ had a clinically-diagnosed gluten intolerance.

Motivations for following a GFD are reported in Table 1 for both categories of respondents who currently follow a GFD and respondents who have followed, but are no longer doing so. Those who reported other motivations included qualifying responses of acne prevention, narcolepsy prevention, migraine prevention 
Table 1.

Comparison of GFD Motivation for Between Current and Former GFD Followers

\begin{tabular}{|c|c|c|c|}
\hline $\begin{array}{l}\text { Motivation for } \\
\text { following a GFD }\end{array}$ & $\begin{array}{l}\text { Previous } \\
\text { GFD } \\
\text { follower } \\
(\mathrm{n}=38)\end{array}$ & $\begin{array}{l}\text { Current } \\
\text { GFD } \\
\text { Follower } \\
(\mathrm{n}=52)\end{array}$ & \\
\hline & $\mathrm{n}(\%)$ & $n(\%)$ & $\chi^{2}(p)$ \\
\hline Medical Diagnosis & $8(28.6)$ & $36(69.2)$ & $\begin{array}{r}12.16 \\
(<0.001)\end{array}$ \\
\hline $\begin{array}{l}\text { celiac } \\
\text { disease }\end{array}$ & $1(3.6)$ & $18(34.6)$ & $\begin{array}{r}9.69 \\
(0.002)\end{array}$ \\
\hline $\begin{array}{l}\text { Crohn’s } \\
\text { disease }\end{array}$ & $0(0.0)$ & $0(0.0)$ & ----- \\
\hline $\begin{array}{l}\text { gluten } \\
\text { intolerance }\end{array}$ & $3(10.7)$ & $23(44.2)$ & $\begin{array}{r}9.32 \\
(0.002)\end{array}$ \\
\hline $\begin{array}{l}\text { wheat } \\
\text { allergy }\end{array}$ & $2(7.1)$ & $6(11.5)$ & $\begin{array}{r}0.39 \\
(0.53)\end{array}$ \\
\hline $\begin{array}{l}\text { irritable } \\
\text { bowel } \\
\text { syndrome }\end{array}$ & $9(32.1)$ & $13(25.0)$ & $\begin{array}{r}0.47 \\
(0.50)\end{array}$ \\
\hline $\begin{array}{c}\text { multiple } \\
\text { diagnoses }\end{array}$ & $3(10.7)$ & $16(30.8)$ & $\begin{array}{r}4.04 \\
(0.04)\end{array}$ \\
\hline General Health & $17(60.7)$ & $29(55.8)$ & $\begin{array}{r}0.18 \\
(0.67)\end{array}$ \\
\hline Weight Loss & $7(25.0)$ & $6(11.5)$ & $\begin{array}{r}2.42 \\
(0.11)\end{array}$ \\
\hline Curiosity & $6(21.4)$ & $5(9.6)$ & $\begin{array}{r}2.14 \\
(0.14)\end{array}$ \\
\hline Other & $4(14.3)$ & $12(23.1)$ & $\begin{array}{r}0.88 \\
(0.35)\end{array}$ \\
\hline
\end{tabular}

inflammatory illness, "self-diagnosed digestive issues," and personal attempts to alleviate symptoms of gluten intolerance or IBS, including constant bloating. When qualifying the choice of "other," participants who had followed a GFD in the past, but no longer were doing so reported seeking fitness gains, being advised to follow a GFD by a chiropractor because of gastrointestinal issues, "gut issues," and psoriasis treatment as reasons for adherence.

One-way ANOVA analyses found that GFD followers with medical diagnoses were significantly more likely ( $<<0.001$ ) to respond strongly to the question "How important to your health are accidental gluten exposures?” and the same was true of GFD followers motivated by general health $(\mathrm{p}=0.004)$ compared to those with other motivations. GFD followers motivated by weight loss were significantly more likely to purposefully eat gluten ( $\mathrm{p}=$ 0.042).

\section{Reasons for Terminating a GFD}

Descriptive analyses revealed that, of those participants who followed a GFD in the past, $32.1 \%$ stopped because it was too difficult, $10.7 \%$ found it to be too expensive, and $10.7 \%$ reported it was too difficult to eat outside of their homes. Reasons for discontinuing a GFD also included missing eating gluten products (28.6\%) or not liking gluten-free foods (7.1\%). The range of time spent on a GFD was 1 week to 10 years.

In response to an open-ended question regarding the decision to terminate a GFD, participants supplied additional reasons than those in the survey checklist, including a desire to drink beer or being "too busy" to follow the diet. One respondent reported only eating gluten "on vacation" because she did not have Celiac. Another followed the diet as part of the Whole30 challenge, a 30-day program requiring the elimination of all processed food, sugar, and alcohol from an individual's diet (Hartwig \& Hartwig, 2009). Some respondents reported beginning the diet with hopes of medical benefits, but discontinuing when there was no improvement in their condition. Some respondents did not care for substitutes, and others found the restriction too difficult. As one participant described: "It's hard to go both dairy and gluten free, so I opted to have a bit of gluten to keep me sane.”

\section{Discussion}

Almost one third of current GFD followers and nearly three-fourths of those who followed a GFD in the past did not have a medical diagnosis. This might suggest underreporting of non-diagnosis, because according to a recent study of nonceliac athletes (NCAs), which found that of the $41 \%$ of NCAs who followed a GFD $50-100 \%$ of the time, $57 \%$ were self-diagnosing gluten sensitivity (Lis, Stellingwerff, Shing, Ahuja, \& Fell, 2015).

The findings of this study suggest that that adherence to a GFD may occur for reasons outside of a medical diagnosis. Strong associations with gluten restriction and 
improved health, wellness, and weight loss suggest a potential misinterpretation of gluten and its effects on the body. While gluten itself may not have nutritional benefits, the whole grains in which it can be found are linked with reduced risks of obesity, cardiovascular disease, Type 2 diabetes, and certain cancers (Jonalgadda, et al. 2011). Based upon qualitative information provided by respondents, it is clear that motivation to adhere to a gluten-free lifestyle can be difficult to sustain. Lesser commitment to a GFD without risk of medical illness is supported by the statistically significant differences on the CDAT found between medically diagnosed and nondiagnosed GFD followers. This may be partially explained by the perception of a GFD as similar to any other weight loss or temporary diet.

Even with a medical prescription for a GFD, adherents should pay careful attention to the nutritional quality of their overall diets to avoid potential negative health outcomes, including under consumption of important dietary nutrients and overconsumption of saturated fats (Kupper, 2005; Thompson, Dennis, Higgins, Lee, \& Sharrett, 2005; Vici, Belli, Biondi, \& Polzonetti, 2016). Public health educators must address misinformation about gluten and GFDs, making it clear that a GFD is a medical prescription for chronic disease, and that following a GFD is a decision that should be discussed with a professional (ADA, 2005; Ansel, 2014; Case, 2005; Kupper, 2005).

\section{Limitations}

This study was conducted entirely online by self-report. It is possible that the study suffered from selection bias, as individuals motivated to take this survey were very interested in glutenfree dieting, and that, along with the use of snowball sampling may have resulted in a higher percentage of celiac patients, resulting in proportions of current GFD adherents, previous GFD followers, and individuals with celiac disease may not accurately represent the general population of current and previous GFD users. Including "check all that apply" as a response option for both motivations to begin the diet and reasons for terminating adherence could have potentially skewed results, and it may have been more impactful to assess a single primary motivation. Additionally, while motivations provide some information about an individual's reasons for choosing the GFD, investigating beliefs and attitudes about gluten-free dieting may more accurately reflect the potential miseducation of the general population.

The study population was small and primarily composed of White females between the ages of 19 and 35 years. It could also be a limitation of using social media and snowball sampling for recruitment, as these findings differ from the DiaGiacomo et al. (2013) study, which found GFD adherence increasing with age. Future studies should attempt to replicate the demographic characteristics of the average GFD adherent.

\section{Conclusions}

Following a GFD is the only known treatment for celiac disease and other clinical digestive disorders. However, the disproportionate number of U.S. adults who are interested in, or are currently following, a GFD, when compared to those following medical recommendations, suggests there are strong motivations for GFD adherence aside from clinical diagnosis. Public health educators must ensure that media messaging and healthy eating programs are clear about the purpose and scientifically proven benefits of gluten-free dieting to avoid unnecessary restriction and potentially negative health outcomes in the general population.

\section{References}

American Dietetic Association. (2005). Response to Food Labeling: Gluten-Free Labeling of Foods; Public Meeting; Request for Comments. Retrieved from http://www.fda.gov/ohrms/dockets/dockets/05n0279/05n-0279-EC1482-Attach-1.pdf

Ansell, K. (2014). Does my child need a gluten free diet? Retrieved from http://www.eatright.org/resource/food/nutrition/vegetarian-and-special-diets/does-my-child-needa-gluten-free-diet 
Case, S. (2005). The gluten-free diet: how to provide effective education and resources. Gastroenterology, 128(4), S128-S134.

DiGiacomo, D. V., Terryson, C. A., Green, P. H., \& Demmert, R. T. (2013). Prevalence of gluten-free diet adherence among individuals without celiac disease in the USA: Results from the Continuous National Health and Nutrition Examination Survey. Scandinavian Journal of Gastroenterology, 48(8), 921-925.

Dunn, C., House, L., \& Shelnutt, K. P. (2014). Consumer perceptions of gluten-free products and the healthfulness of gluten-free diets. Journal of Nutrition Education and Behavior, 46(4), S184S185.

Fasano, A., Berti, I., Gerarduzzi, T., Not, T., Colletti, R. B., Drago, S., Elitsur, Y., Green, P. H., Guandalini, S., Hill, I. D., \& Pietzak, M. (2003). Prevalence of celiac disease in at-risk and not-atrisk groups in the United States: A large multicenter study. Archives of Internal Medicine, 163(3), 286-92.

Fasano, A., Sapone, A., Zevallos, V., \& Schuppan, D. (2015). Nonceliac gluten sensitivity. Gastroenterology, 148(6), 1195-204.

Godfrey, J. D., Brantner, T. L., Brinjikji, W., Christensen, K. N., Brogan, D. L., Van Dyke, C. T., Lahr, B. D., Larson, J. J., Rubio-Tapia, A., Melton, L. J., \& Zinsmeister, A. R. (2010). Morbidity and mortality among older individuals with undiagnosed celiac disease. Gastroenterology, 139(3), 763-9.

Hallert, C., Svensson, M., Tholstrup, J., \& Hultberg, B. (2009). Clinical trial: B vitamins improve health in patients with coeliac disease living on a gluten-free diet. Alimentary Pharmacology \& Therapeutics, 29(8), 811-16.

Hartwig, M, \& Hartwig, D. (2015). The Whole30: The 30-Day Guide to Total Health and Food Freedom. New York, New York: Houghton-Mifflin Harcourt.

Howard, M. R., Turnbull, A. J., Morley, P., Hollier, P., Webb, R., \& Clarke, A. (2002). A prospective study of the prevalence of undiagnosed coeliac disease in laboratory defined iron and folate deficiency. Journal of Clinical Pathology, 55(10), 754-7.

Jonnalagadda, S. S., Harnack, L., Liu, R. H., McKeown, N., Seal, C., Liu, S., \& Fahey, G. C. (2011). Putting the whole grain puzzle together: health benefits associated with whole grains-summary of American Society for Nutrition 2010 Satellite Symposium. The Journal of Nutrition, 141(5), 1011S-1022S.

Kliewer, K. L., Venter, C., Cassin, A. M., Abonia, J. P., Aceves, S. S., Bonis, P. A., Dellon, E.S., Falk, G.W., Furuta, G.T., Gonsalves, N., Gupta, S. K., Hirano, I., Kagalwalla, A., Leung, J., Mukkada, V.A., Spergel. J.M., \& Rothenberg, M.E.(2016). Should wheat, barley, rye, and/or gluten be avoided in a 6-food elimination diet?. Journal of Allergy and Clinical Immunology, 137(4), 10111014.

Kupper, C. (2005). Dietary guidelines and implementation for celiac disease.Gastroenterology, 128(4), S121-S127.

Leffler, D. A., Dennis, M., Edwards, G., Jamma, S., Magge, S., Cook, E. F., Shuppan, D., \& Kelly, C. P. (2009). Simple validated gluten-free diet adherence survey for adults with celiac disease. Gastroenterology \& Hepatology, 7(5), 530-536.

Lis, D. M., Stellingwerff, T., Shing, C. M., Ahuja, K. D. K., \& Fell, J. W. (2015). Exploring the popularity, experiences, and beliefs surrounding gluten-free diets in nonceliac athletes. International Journal of Sport Nutrition and Exercise Metabolism, 25, 37-45.

Ludvigsson, J. F., Leffler, D. A., Bai, J. C., Biagi, F., Fasano, A., Green, P. H., Hadjivassiliou, M., Kaukinen, K., Kelly, C. P., Leonard, J. N., \& Lundin, K.E.A. (2012). The Oslo definitions for coeliac disease and related terms. Gut, 62(1), 43-52.

Marshall, R. (2014). Bio field diet: grains. The Quantum Summit. Quantum Reflex Analysis, Advanced Seminar. Premier Research Labs. Austin, Texas.

Ohlund, K., Olsson, C., Hernell, O., \& Ohlund, I. Dietary short-comings in children on a gluten-free diet. (2010). Journal of Human Nutrition \& Dietetics, 23(3), 294-300. 
Priven M., Baum J., Vieira E, Fung, T., \& Herbold, N. (2015). The influence of a factitious free-from food product label on consumer perceptions of healthfulness. Journal of the Academy of Nutrition and Dietetics 115(11), 1808-1814.

Rubio-Tapia, A., Kyle, R. A., Kaplan, E. L., Johnson, D. R., Page, W., Erdtmann, F., Brantner, T.L., Kim, W.R., Phelps, T.K., Lahr, B.D., \& Zinsmeister, A.R. (2009). Increased prevalence and mortality in undiagnosed celiac disease. Gastroenterology, 137(1), 88-93.

Sapone, A., Bai, J. C., Ciacci, C., Dolinsek, J., Green, P. H., Hadjivassiliou, M., Kaukinen, K., Rostami, K., Sanders, D.S., Schumann, M., \& Ullrich, R. (2012). Spectrum of gluten-related disorders: consensus on new nomenclature and classification. BMC Medicine, 10(13). doi: 10.1186/17417015-10-13

Thompson, T., Dennis, M., Higgins, L. A., Lee, A. R., \& Sharrett, M. K. (2005). Gluten-free diet survey: are Americans with coeliac disease consuming recommended amounts of fibre, iron, calcium and grain foods?.Journal of Human Nutrition and Dietetics, 18(3), 163-169.

Vici, G., Belli, L., Biondi, M., \& Polzonetti, V. (2016). Gluten free diet and nutrient deficiencies: A review. Clinical Nutrition. (In Press)

Wild, D., Robins, G. G., Burley, V. J., \& Howdle, P. D. (2010). Evidence of high sugar intake, and low fibre and mineral intake, in the gluten-free diet. Alimentary Pharmacology \& Therapeutics, 32(4), 573- 81.

\author{
Author Information \\ Sarah E. Pember \\ Credentials: MT, CHES \\ Title: Doctoral Candidate \\ Mailing Address \& Contact Information: \\ The University of Alabama \\ Department of Health Science \\ PO Box 870311 \\ Tuscaloosa, AL 35487 \\ (205) 348-9087 \\ sepember@crimson.ua.edu \\ * corresponding author
}

